\title{
Predictors of health-related quality of life after burn injuries: a systematic review
}

\author{
Inge Spronk ${ }^{1,2^{*}}$ (D), Catherine M. Legemate ${ }^{1,3}$, Jan Dokter ${ }^{4}$, Nancy E. E. van Loey ${ }^{5,6}$, Margriet E. van Baar ${ }^{1,2}$ \\ and Suzanne Polinder ${ }^{2}$
}

\begin{abstract}
Background: Identifying predictors of health-related quality of life (HRQL) following burns is essential for optimization of rehabilitation for burn survivors. This study aimed to systematically review predictors of HRQL in burn patients.

Methods: Medline, Embase, Web of Science, Cochrane, CINAHL, and Google Scholar were reviewed from inception to October 2016 for studies that investigated at least one predictor of HRQL after burns. The Quality in Prognostic Studies tool was used to assess risk of bias of included studies.

Results: Thirty-two studies were included. Severity of burns, postburn depression, post-traumatic stress symptoms, avoidance coping, less emotional or social support, higher levels of neuroticism, and unemployment postburn were found to predict a poorer HRQL after burns in multivariable analyses. In addition, weaker predictors included female gender, pain, and a postburn substance use disorder. Risk of bias was generally low in outcome measurement and high in study attrition and study confounding.

Conclusions: HRQL after burns is affected by the severity of burns and the psychological response to the trauma. Both constructs provide unique information and knowledge that are necessary for optimized rehabilitation. Therefore, both physical and psychological problems require attention months to years after the burn trauma.
\end{abstract}

Keywords: Burn injuries, Health-related quality of life, Predictors

\section{Background}

Health-related quality of life (HRQL) is an important outcome measure of burns in both the short- and long-term $[1,2]$ and is increasingly studied. HRQL is a multidimensional concept that reflects an individual's perception of how a disease affects his/her physical, psychological, and social well-being [3-5]. Insight into which factors determine HRQL after burns is useful for clinical practice, research, and policy making. Conceptual models have been developed in order to better understand $\mathrm{HRQL}$ and the variables that relate to HRQL in general [3, 6-8]. According to the revised Wilson and Clearly model for health-related quality of life, HRQL is influenced by individual and environmental characteristics, biological function, symptoms, functional status,

\footnotetext{
*Correspondence: spronki@maasstadziekenhuis.nl

'Association of Dutch Burn Centres, Maasstad Hospital, Maasstadweg 21, 3079 DZ Rotterdam, the Netherlands

2Department of Public Health, Erasmus Medical Centre, 's-Gravendijkwal 230, 3015 CE Rotterdam, the Netherlands

Full list of author information is available at the end of the article
}

and general health perceptions [3]. A recent study confirmed that this model is also applicable to burns [9].

Burns can have a considerable negative impact on daily activities and on both physical and psychosocial functioning [10-12]. HRQL domains are often impaired in the short-term. Most domains of HRQL improve in the longer-term, but also in the longer-term some aspects (e.g., physical and emotional role participation) have poor outcomes [13-15]. Burn injuries are thus associated with a significant physical and psychological burden.

The prediction of an individual's ability to adjust to the consequences of their burn injury is important. Information regarding these predictors may help caregivers in selecting patients who require special attention in rehabilitation and in preparing patient-specific care plans [16]. Predictors of HRQL following burns have been examined in individual studies, but predictors of HRQL have not been systematically reviewed in the field of burns. Potential meaningful factors are the patient's age 
and gender, percentage total body surface area (\%TBSA) burned, length of hospital stay, body area affected, time since injury, and psychological impact of burns. However, it is not yet clear which predictive factors are most important [17-20]. Earlier recent reviews focused on the evolution and relevance of one specific HRQL instrument in burns [21], on HRQL outcomes in burns [19], and on HRQL instruments used and recovery patterns of HRQL in burns, without studying predictors. Therefore, the aim of the present study is to systematically review predictors of HRQL following burn injuries.

\section{Methods}

This systematic review was conducted and is reported in line with the Preferred Reporting Items for Systematic Reviews and Meta-analyses (PRISMA) Statement [22] and has been registered on PROSPERO (ID CRD42016048065).

\section{Search strategy and inclusion criteria}

The databases Medline, Embase, Web of Science, Cochrane, CINAHL, and Google Scholar were systematically searched using terms covering HRQL and burns (search strategy provided in Additional file 1) in October 2016. The search strategy was developed in collaboration with an experienced librarian. Original prognostic studies conducted in adult burn patients and focusing on at least one predictor of HRQL after burns were included. Studies had to be published in a peer-reviewed journal and written in English and were required to have used a generic or burn-specific instrument to assess HRQL. Outcomes had to be a regression or correlation coefficient of the relation of a predictor with HRQL. All kinds of predictors were considered.

\section{Selection of studies and data extraction}

An experienced librarian performed the systematic search. After removal of duplicates, relevant articles were selected on the basis of title by one researcher (IS). Ten percent of the abstracts were independently evaluated by two researchers (IS and CL). Perfect agreement on inclusion was achieved (Cohen's kappa coefficient $=1$ ); therefore, one researcher evaluated the remaining abstracts (IS) [23]. In case of any doubt, a title or abstract was screened by a second researcher. Two researchers (IS and CL) independently performed screening of full text and extraction of data. The screening of these three steps was performed using the above mentioned inclusion criteria.

Data extraction included study characteristics (study type, country, sample size, assessment time points, length of follow-up), patient and burn characteristics (age, gender, hospital length of stay (LOS), \%TBSA), details on HRQL instruments (type, number, general burn-specific HRQL, proxy), and predictors (number of predictors assessed, univariable and multivariable predictors, statistical methods). Discrepancies arising from decisions around inclusion or extraction of data were discussed with a third researcher (MvB) until resolved.

\section{Risk of bias}

The Quality in Prognostic Studies (QUIPS) tool [24] was used to assess the risk of bias of the included studies. Two researchers (IS and CL) independently assessed the risk of bias of the six domains. The domains were rated as either low, moderate, or high risk of bias. A low risk was obtained when all items of a domain were scored as "low risk" [24]. A moderate risk was obtained when at least one up to a maximum of half of the items were rated as high or had an unknown risk of bias. A high risk was obtained when more than half of the items were rated as high or had an unknown risk of bias. Disagreements were resolved by discussion with a third researcher $(\mathrm{MvB})$.

\section{Data analysis}

First the characteristics and the risk of bias of all studies were tabulated. Then the predictor findings of studies using multivariable analysis were analyzed. Multivariable models were models that included at least two factors to predict HRQL. Predictors were divided into four categories: demographic, environmental, burn-specific, and psychological factors. If it was unclear whether associations were significant $(p \leq 0.05)$, results could not be included in our analysis. When more than one time point was used, the point closest to the most often used time points in other studies was chosen. Given the heterogeneity of predictors, HRQL instruments, and statistical reporting, meta-analyses could not be conducted. Therefore, a more qualitative approach was used: all predictors of each study were summarized on the basis of their direction and statistical significance [25, 26]. Predictors were scored having no statistically significant association $(p>0.05)$ with HRQL, a significant association $(p \leq 0.05)$ with a subscale of the HRQL instrument, or a significant association with the total HRQL instrument. Associations with the total HRQL instrument were weighted more heavily (Table 3). Due to the wide variety of predictors assessed among the included studies, only those predictors that were studied in more than one study were tabulated (Table 3). Predictors were considered strong when $\geq 67 \%$ of the associations were in the same direction and statistically significant and weak if $\geq 33$ to $<67 \%$ of the associations fulfilled these conditions.

\section{Results}

\section{Search results}

The initial database search netted 6173 records, including 3788 unique articles. Screening of titles and 
abstracts resulted in 144 potentially relevant articles (Fig. 1). Thirty-two of these were eligible after reading the full text. The main reason for exclusion was not studying predictors.

\section{Study characteristics}

Sample sizes varied between 20 and 1051 patients, with most studies $(75 \%)$ having a sample size below 200 patients (Table 1). In all except one study [27], more males than females were included. The mean \%TBSA burned ranged from 8 to $84 \%$. Eleven different HRQL instruments were used in the included studies. The most often used instruments were the Burn-specific Health Scale-Brief (BSHS-B; $n=17$ ) and the Medical Outcome Study Short Form-36 items $($ SF-36; $n=11)$. Eighteen studies measured HRQL at one time point, whereas 13 measured HRQL two to six times. One study failed to describe their assessment point. The most used time points were at 3 months $(n=6), 6$ months $(n=11)$, 12 months $(n=12)$, and 24 months $(n=7)$. Seventeen studies used an assessment point more than one year after the burn injury.

\section{Risk of bias}

The quality of included studies was in general moderate. In most studies risk of bias was moderate or high for the items "study attrition" and "study confounding" (Table 2). Positive aspects of the studies were the low risk of bias for the items "outcome measurement" and "statistical analysis and reporting". None of the studies scored a low risk of bias on all items and one study had a low risk on all but one dimension [28].

\section{Predictors of HRQL}

Twenty studies used multivariable analysis. One study [29] did not indicate significant $(p \leq 0.05)$ predictors and was therefore not included in our analyses. Three studies applied two different HRQL instruments, resulting in 22 different prediction studies. Eleven of these studies were based on four cohorts. Due to the low number of studies, all of these studies were included in the examination. The studies investigated between five and 42 predictors. Overall, 114 different predictors were investigated, of which 38 were studied in more than one study (Fig. 2). These were 16 burn-specific, 12 psychological, six demographic, and four environmental factors (Table 3, Additional file 2).

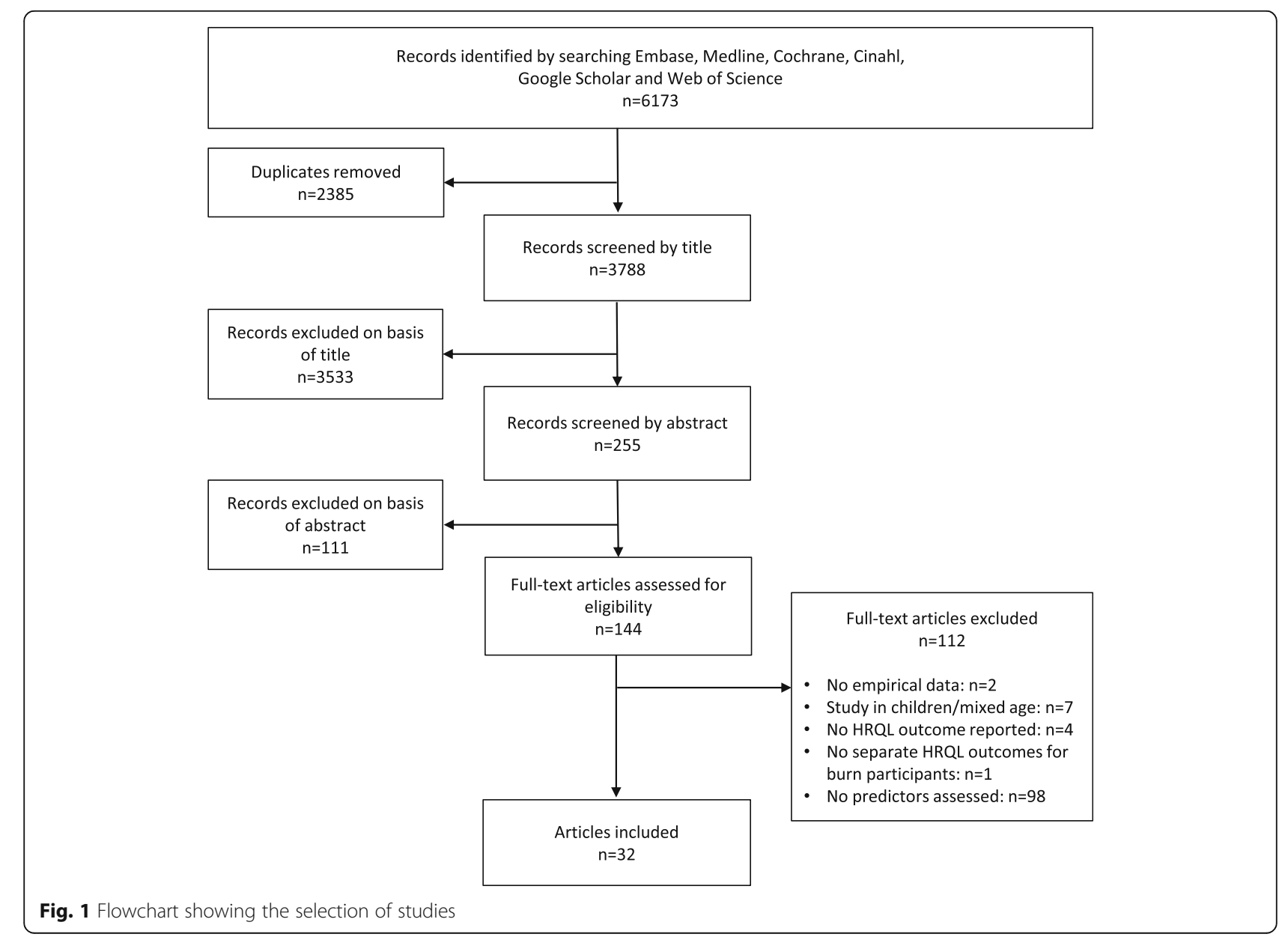


Table 1 Characteristics of included studies $(n=32)$

\begin{tabular}{|c|c|c|c|c|c|}
\hline Study & Country & Study population ${ }^{a}$ & $\begin{array}{l}\text { Mean \%TBSA } \\
\text { burned (SD) }\end{array}$ & $\begin{array}{l}\text { HRQL } \\
\text { instrument(s) }\end{array}$ & Assessment time point(s) \\
\hline Ahuja et al. 2016 [27] & India & $\begin{array}{l}n=60(\mathrm{M}, 40 \%) . \\
\text { Age, } 18-65 \text { years } \\
\text { (median, } 28 \text { years) }\end{array}$ & Median, 30\% & BSHS-RBA & Median, 10 months \\
\hline Anzarut et al. 2005 [53] & Canada & $\begin{array}{l}n=47(\mathrm{M}, 96 \%) . \\
\text { Mean age } 28 \text { years }\end{array}$ & $64 \%(2)$ & BSHS-A, SF-36 & $\geq 2$ years after discharge \\
\hline Blalock et al. 1994 [54] & USA & $\begin{array}{l}n=254(M, 74 \%) . \\
\text { Mean age } 39 \text { years }\end{array}$ & $19 \%(15)$ & BSHS & Mean, 8-9 months \\
\hline Corry et al. 2010 [55] & USA & $\begin{array}{l}n=171(\mathrm{M}, 70 \%) \\
\text { Age, } 8-86 \text { years } \\
\text { (mean, } 42 \text { years) }\end{array}$ & $\begin{array}{l}15 \%(13) ; \text { range, } \\
1-74 \%\end{array}$ & SF-36 & $\begin{array}{l}\text { Discharge, 1, 6, 12, and } 24 \\
\text { months }^{c}\end{array}$ \\
\hline Cromes et al. 2002 [56] & USA & $\begin{array}{l}n=110(\mathrm{M}, 84 \%) . \\
\text { Mean age } 38 \text { years }\end{array}$ & $24 \%$ & BSHS & $2^{d}, 6^{d}$, and $12^{d}$ months \\
\hline Edgar et al. 2013 [17] & Australia & $\begin{array}{l}n=1051,(\mathrm{M}, 80 \%) \\
\text { Age, } 15-89 \text { years } \\
\text { (mean, } 37 \text { years) }\end{array}$ & $\begin{array}{l}8 \%(11) ; \text { range, } \\
0-75 \%\end{array}$ & BSHS-B, SF-36 & $1,3,6,12$, and 24 months $^{c}$ \\
\hline Ekeblad et al. 2015 [29] & Sweden & $\begin{array}{l}n=107(\mathrm{M}, 75 \%) \\
\text { Age, } 19-89 \text { years } \\
\text { (mean } 43 \text { years) }\end{array}$ & $23 \%$; range $1-80 \%$ & $\begin{array}{l}\text { BSHS-B, EQ-5D, } \\
\text { SF-36 }\end{array}$ & 12 months \\
\hline Finlay et al. 2014 [57] & Australia & $\begin{array}{l}n=927(\mathrm{M}, 73 \%) . \\
\text { Age, } 16-83 \text { years } \\
\text { (mean, } 32 \text { years) }\end{array}$ & $7 \%(10)$ & BSHS-B & $\begin{array}{l}\text { Discharge, } 1,3^{d}, 6,12 \text {, } \\
\text { and } 24 \text { months }\end{array}$ \\
\hline Finlay et al. 2015 [58] & Australia & $\begin{array}{l}n=224(\mathrm{M}, 83 \%) . \\
\text { Age, } 16-84 \text { years } \\
\text { (median } 36 \text { years) }\end{array}$ & $\begin{array}{l}\text { Median, 4\%; range } \\
\text { 1-60\% }\end{array}$ & BSHS-B & NA \\
\hline Kildal et al. 2001 [59] & Sweden & $\begin{array}{l}n=248(M, 80 \%) . \\
\text { Mean age } 37 \text { years }\end{array}$ & $23 \%(16)$ & BSHS-B & $\begin{array}{l}\text { Mean, } 9.3 \text { years } \\
\text { (SD } 4.8 \text { years) }\end{array}$ \\
\hline Kildal et al. 2004 [60] & Sweden & $\begin{array}{l}n=166(M, 80 \%) . \\
\text { Mean age } 50 \text { years }\end{array}$ & $25 \%(16)$ & BSHS-B & $\begin{array}{l}\text { Mean, } 11.4 \text { years; range, } \\
3-19 \text { years }\end{array}$ \\
\hline Kildal et al. 2005 [61] & Sweden & $\begin{array}{l}n=161(\mathrm{M}, 79 \%) . \\
\text { Age, } 17-79 \text { years } \\
\text { (mean, } 48 \text { years) }\end{array}$ & $\begin{array}{l}24 \%(16) ; \text { range, } \\
1-85 \%\end{array}$ & BSHS-B & $\begin{array}{l}\text { Mean, } 9.2 \text { years; range } \\
1-18 \text { years }\end{array}$ \\
\hline Knight et al. 2017 [62] & Australia & $\begin{array}{l}n=41(M, 81 \%) . \\
\text { Age, } 19-81 \text { years } \\
\text { (mean, } 45 \text { years) }\end{array}$ & $8 \%$ & BSHS-B & 12-24 months \\
\hline Leblebici et al. 2006 [63] & Turkey & $\begin{array}{l}n=22(\mathrm{M}, 64 \%) . \\
\text { Mean age } 25 \text { years }\end{array}$ & $28 \%(17)$ & SF-36 & Mean, 21 months \\
\hline Low et al. 2012 [64] & Sweden & $\begin{array}{l}n=85(\mathrm{M}, 75 \%) . \\
\text { Age, } 19-89 \text { years } \\
\text { (mean, } 45 \text { years) }\end{array}$ & $\begin{array}{l}24 \%(20) ; \text { range, } \\
1-80 \%\end{array}$ & BSHS-B & 12 months \\
\hline Moi et al. 2007 [65] & Norway & $\begin{array}{l}n=95(M, 82 \%) . \\
\text { Mean age } 44 \text { years }\end{array}$ & $19 \%(14)$ & BSHS-A & $\begin{array}{l}\text { Mean, } 47 \text { months } \\
\text { (SD } 24 \text { months) }\end{array}$ \\
\hline Moi and Nilsen 2012 [9] & Norway & $\begin{array}{l}n=95(\mathrm{M}, 82 \%) . \\
\text { Mean age } 44 \text { years }\end{array}$ & $19 \%(14)$ & $\begin{array}{l}\text { BSHS-A, SF-36, } \\
\text { QOLS }\end{array}$ & $\begin{array}{l}\text { Mean, } 47 \text { months } \\
\text { (SD } 24 \text { months) }\end{array}$ \\
\hline Novelli et al. 2009 [66] & Italy & $\begin{array}{l}n=30(\mathrm{M}, 60 \%) . \\
\text { Mean age } 42 \text { years }\end{array}$ & $32 \%(13)$ & SIP & Discharge, 3 months ${ }^{d}$ \\
\hline Orwelius et al. 2013 [28] & Sweden & $\begin{array}{l}n=156(M, 74 \%) \\
\text { Age, } 16-90 \text { years } \\
\text { (mean, } 46 \text { years) }\end{array}$ & $\begin{array}{l}\text { 24\% (19); range, } \\
0-80 \%\end{array}$ & SF-36 & $12^{\mathrm{d}}$ and 24 months \\
\hline Oster et al. 2011 [18] & Sweden & $\begin{array}{l}n=89(M, 77 \%) . \\
\text { Mean age } 43 \text { years }\end{array}$ & $25 \%(20)$ & $E Q-5 D$ & $\begin{array}{l}\text { Admission, } 3,6,12 \text { months, } \\
\text { and } 2 \text { to } 7^{d} \text { years }\end{array}$ \\
\hline Oster et al. 2013 [30] & Sweden & $\begin{array}{l}n=67(M, 78 \%) . \\
\text { Mean age } 43 \text { years }\end{array}$ & $25 \%(20)$ & BSHS-B & $\begin{array}{l}6 \text { and } 12 \text { months and } 2 \text { to } \\
7^{d} \text { years }\end{array}$ \\
\hline Palmu et al. 2015 [67] & Finland & $\begin{array}{l}n=92(\mathrm{M}, 70 \%) . \\
\text { Mean age } 46 \text { years }\end{array}$ & $10 \%$ & $\begin{array}{l}\text { 15D, EQ-5D, } \\
\text { RAND-36 }\end{array}$ & 6 months \\
\hline
\end{tabular}


Table 1 Characteristics of included studies $(n=32)$ (Continued)

\begin{tabular}{|c|c|c|c|c|c|}
\hline Study & Country & Study population ${ }^{a}$ & $\begin{array}{l}\text { Mean \%TBSA } \\
\text { burned (SD) }\end{array}$ & $\begin{array}{l}\mathrm{HRQL} \\
\text { instrument(s) }\end{array}$ & Assessment time point(s) \\
\hline Renneberg et al. 2014 [68] & Germany & $\begin{array}{l}n=265(M, 72 \%) . \\
\text { Age, } 16-73 \text { years } \\
\text { (mean, } 39 \text { years) }\end{array}$ & $\begin{array}{l}14 \%(14) ; \text { range, } \\
1-76 \%\end{array}$ & BSHS-B, SF-12 & $\begin{array}{l}\text { Admission, } 6,12,24, \\
\text { and } 36 \text { months }^{c}\end{array}$ \\
\hline Ricci et al. 2014 [69] & Brazil & $\begin{array}{l}n=73(\mathrm{M}, 69 \%) \\
\text { Mean age } 38 \text { years }\end{array}$ & $14 \%(12)$ & BSHS-R & 5 to 7 months \\
\hline Roh et al. 2012 [70] & South Korea & $\begin{array}{l}n=113(\mathrm{M}, 71 \%) . \\
\text { Mean age } 38 \text { years }\end{array}$ & $14 \%(12)$ & BSHS-B & 1 month \\
\hline Tahir et al. 2011 [71] & Pakistan & $\begin{array}{l}\mathrm{n}=99(\mathrm{M}, 68 \%) . \\
\text { Age, } 19-57 \text { years } \\
\text { (median, } 30 \text { years) }\end{array}$ & $\begin{array}{l}19 \% \text {, range; } \\
5-38 \%\end{array}$ & SF-36 & $\begin{array}{l}\text { Admission, } 5 \text { and } 6^{d} \\
\text { months }\end{array}$ \\
\hline Van Loey et al. 2012 [20] & $\begin{array}{l}\text { The Netherlands } \\
\text { and Belgium }\end{array}$ & $\begin{array}{l}n=244(\mathrm{M}, 73 \%) \\
\text { Mean age } 39 \text { years }\end{array}$ & $\begin{array}{l}12 \%(11) ; \text { range } \\
1-65 \%\end{array}$ & $E Q-5 D$ & $\begin{array}{l}3 \text { weeks, 3, 9, and } 18 \\
\text { months }\end{array}$ \\
\hline Wasiak et al. 2014 [72] & Australia & $\begin{array}{l}n=99(\mathrm{M}, 75 \%) . \\
\text { Mean age } 42 \text { years }\end{array}$ & $19 \%$ & BSHS-B, SF-36 & Preburn and $12^{\mathrm{d}}$ months \\
\hline Willebrand et al. 2006 [73] & Sweden & $\begin{array}{l}n=86(\mathrm{M}, 73 \%) . \\
\text { Age, } 15-85 \text { years } \\
\text { (mean, } 43 \text { years) }\end{array}$ & $17 \%(14)$ & BSHS-B & $\begin{array}{l}\text { Mean, } 3.6 \text { years } \\
\text { (SD } 1.2 \text { years) }\end{array}$ \\
\hline Willebrand and Ekselius 2011 [74] & Sweden & $\begin{array}{l}n=94(\mathrm{M}, 76 \%) . \\
\text { Age, } 19-90 \text { years } \\
\text { (mean, } 44 \text { years) }\end{array}$ & $23 \%(20)$ & BSHS-B, SF-36 & $6^{d}, 12^{d}$, and $24^{d}$ months \\
\hline Xie et al. 2012 [75] & China & $\begin{array}{l}n=20(\mathrm{M}, 70 \%) . \\
\text { Mean age } 43 \text { years }\end{array}$ & $84 \%(10)$ & BSHS-B, SF-36 & $\geq 2$ years after discharge \\
\hline Zhang et al. 2014 [33] & China & $\begin{array}{l}n=208(M, 77 \%) \\
\text { Mean age } 42 \text { years }\end{array}$ & $42 \%(27)$ & BSHS-B & $\geq 2$ years after discharge \\
\hline
\end{tabular}

${ }^{a}$ Study population: $n$ sample size; $M$ males; $N A$ not applicable

${ }^{\mathrm{b}} 15 D$ 15-dimensional health-related quality of life instrument, BSHS Burn-specific Health Scale, BSHS-A Burn-specific Health Scale-Abbreviated, $B S H S-B$ Burn-specific Health Scale-Brief, BSHS-RBA Burn-specific Health Scale Revised, Brief and Adapted, EQ-5D EuroQol five dimensions questionnaire, RAND-36 RAND 36-item health survey, SIP Sickness Impact Profile, SF-10 Medical Outcome Study Short Form-10 items, SF-12 Medical Outcome Study Short Form-12 items, SF-36 Medical Outcome Study Short Form-36 items, QOLS Quality of Life Scale

${ }^{c}$ All measurement points were used as the dependent variable was long-term recovery pattern

${ }^{d}$ Measurement point used for predictor analysis in studies with $\geq 1$ measurement point

\section{Demographic factors}

The most studied demographic factors were age $(n=21)$ and gender $(n=21)$. The studies were inconsistent on whether age is a predictor for HRQL. Among the studies that studied gender, 11 found that male gender was associated with a better HRQL and three reported an association but failed to describe the direction. Marital status, living alone, rehabilitation, and level of education had no significant association with HRQL.

\section{Environmental factors}

The only environmental factor that showed an association with HRQL was postburn working status [18, 30]. Four studies reported that having a job postburn was associated with a better HRQL, and two did not find an association. Preburn working status was only found to relate to a better HRQL in one of the four studies examining this predictor and none of the studies found a relation between socioeconomic status or work-related injury and HRQL.

\section{Burn-specific factors}

The \%TBSA burned is the most often studied burn-specific predictor $(n=18)$. Twelve studies found no association with HRQL, whereas five found a lower HRQL in more severely burned patients and one failed to describe the direction of the association. Somewhat more evidence exists on the LOS. Seven out of the 13 studies reported a lower HRQL after a longer LOS. Both surgery and number of surgeries were studied as predictors. Two studies reported a positive association between surgery and HRQL, whereas one study reported a negative association and one did not find an association. A higher number of surgeries resulted in a decreased HRQL in two studies. Three other studies, however, found no statistically significant association. Five individual predictors (LOS, \%TBSA burned, full-thickness injury, surgery, and number of surgeries) are all indicators of burn severity. The cluster burn severity is a significant predictor of a diminished HRQL in 13 out of the 18 studies that investigated this predictor. Having pain as a predictor was investigated in five studies. Two found that patients that reported pain had a lower HRQL and three did not find an association. Evidence on other burn factors, including full-thickness injury, time since burn, hand burns, face needing grafting, upper limb burns, and mechanical ventilation was inconsistent. Studies found no association 
Table 2 Risk of bias assessment according to the Quality of Prognostic Studies (QUIPS) tool $(n=32)$

\begin{tabular}{|c|c|c|c|c|c|c|c|}
\hline Study & Study Participation & Study attrition & $\begin{array}{l}\text { Prognostic factor } \\
\text { measurement }\end{array}$ & $\begin{array}{l}\text { Outcome } \\
\text { measurement }\end{array}$ & $\begin{array}{l}\text { Study } \\
\text { confounding }\end{array}$ & $\begin{array}{l}\text { Statistical analysis } \\
\text { and reporting }\end{array}$ & $\begin{array}{l}\text { Total } \\
\text { score }\end{array}$ \\
\hline Ahuja et al. 2016 [27] & Low & Low & Moderate & Low & Moderate & Low & 8 \\
\hline Anzarut et al. 2005 [53] & Moderate & Moderate & Moderate & Moderate & High & Moderate & 13 \\
\hline Blalock et al. 1994 [54] & Moderate & High & Moderate & Low & High & Low & 11 \\
\hline Corry et al. 2010 [55] & Moderate & High & Low & Low & Moderate & Low & 10 \\
\hline Cromes et al. 2002 [56] & Moderate & High & Moderate & Low & High & Moderate & 13 \\
\hline Edgar et al. 2013 [17] & Low & Low & Moderate & Low & Moderate & Low & 8 \\
\hline Ekeblad et al. 2015 [29] & Low & Moderate & High & Low & High & Low & 11 \\
\hline Finlay et al. 2014 [57] & Low & Moderate & Low & Low & Moderate & Low & 8 \\
\hline Finlay et al. 2015 [58] & Low & Moderate & Low & Low & Moderate & Low & 8 \\
\hline Kildal et al. 2001 [59] & Low & Moderate & Moderate & Low & Moderate & Low & 9 \\
\hline Kildal et al. 2004 [60] & Low & Moderate & Moderate & Low & Moderate & Low & 9 \\
\hline Kildal et al. 2005 [61] & Low & High & Moderate & Low & Moderate & Low & 10 \\
\hline Knight et al. 2017 [62] & Moderate & High & Low & Low & Low & Low & 9 \\
\hline Leblebici et al. 2006 [63] & Moderate & High & Moderate & Low & Low & Low & 10 \\
\hline Low et al. 2012 [64] & Low & Moderate & Low & Low & Moderate & Low & 8 \\
\hline Moi et al. 2007 [65] & Low & Moderate & Low & Low & Moderate & Low & 8 \\
\hline Moi and Nilsen 2012 [9] & Low & Moderate & Moderate & Low & Moderate & Low & 9 \\
\hline Novelli et al. 2009 [66] & High & High & Moderate & Low & High & Moderate & 14 \\
\hline Orwelius et al. 2013 [28] & Low & Moderate & Low & Low & Low & Low & 7 \\
\hline Oster et al. 2011 [18] & Low & Moderate & Moderate & Low & Moderate & Low & 9 \\
\hline Oster et al. 2013 [30] & Low & Moderate & Moderate & Low & Moderate & Low & 9 \\
\hline Palmu et al. 2015 [67] & Low & Moderate & Low & Low & Moderate & Moderate & 9 \\
\hline Renneberg et al. 2014 [68] & Moderate & High & Low & Low & Low & Low & 9 \\
\hline Ricci et al. 2014 [69] & Moderate & High & Moderate & Low & Moderate & Low & 11 \\
\hline Roh et al. 2012 [70] & Moderate & High & Low & Low & Low & Low & 9 \\
\hline Tahir et al. 2011 [71] & Low & High & Moderate & Low & High & Moderate & 12 \\
\hline Van Loey et al. 2012 [20] & Low & High & Low & Low & Moderate & Low & 9 \\
\hline Wasiak et al. 2014 [72] & Low & High & Low & Low & Moderate & Low & 9 \\
\hline Willebrand et al. 2006 [73] & Low & High & Moderate & Low & Moderate & Low & 10 \\
\hline Willebrand and Ekselius 2011 [74] & Low & Moderate & Moderate & Low & Moderate & Low & 9 \\
\hline Xie et al. 2012 [75] & Moderate & Moderate & Low & Low & Low & Low & 8 \\
\hline Zhang et al. 2014 [33] & Low & Moderate & Moderate & Low & Moderate & Moderate & 10 \\
\hline
\end{tabular}

The total score was composed of the sum of the domain scores, with low risk $=1$, moderate risk $=2$, and high risk $=3$

between either etiology, hands needing grafting, facial burns, or tracheostomy required and HRQL.

\section{Psychological factors}

Postburn depression or depressive symptoms and any preburn psychiatric disorder were the most often studied psychological factors $(n=6)$. Four out of the six studies that investigated postburn depression reported an association with impaired HRQL. Evidence also exists for higher levels of neuroticism and avoidance coping as predictors. The three studies that investigated these predictors all reported associations with poorer HRQL. Posttraumatic stress symptoms and less emotional or social support were also associated with diminished HRQL in the majority of studies. There was less evidence on preburn psychological factors (any psychiatric disorder, depression, substance use disorder, and anxiety disorder) and HRQL. Studies were inconsistent on postburn substance use disorder as a predictor and no association was found between any postburn psychiatric disorder and HRQL.

\section{Discussion}

This study aimed to systematically review predictors of HRQL following burn injuries. Thirty-two studies were 


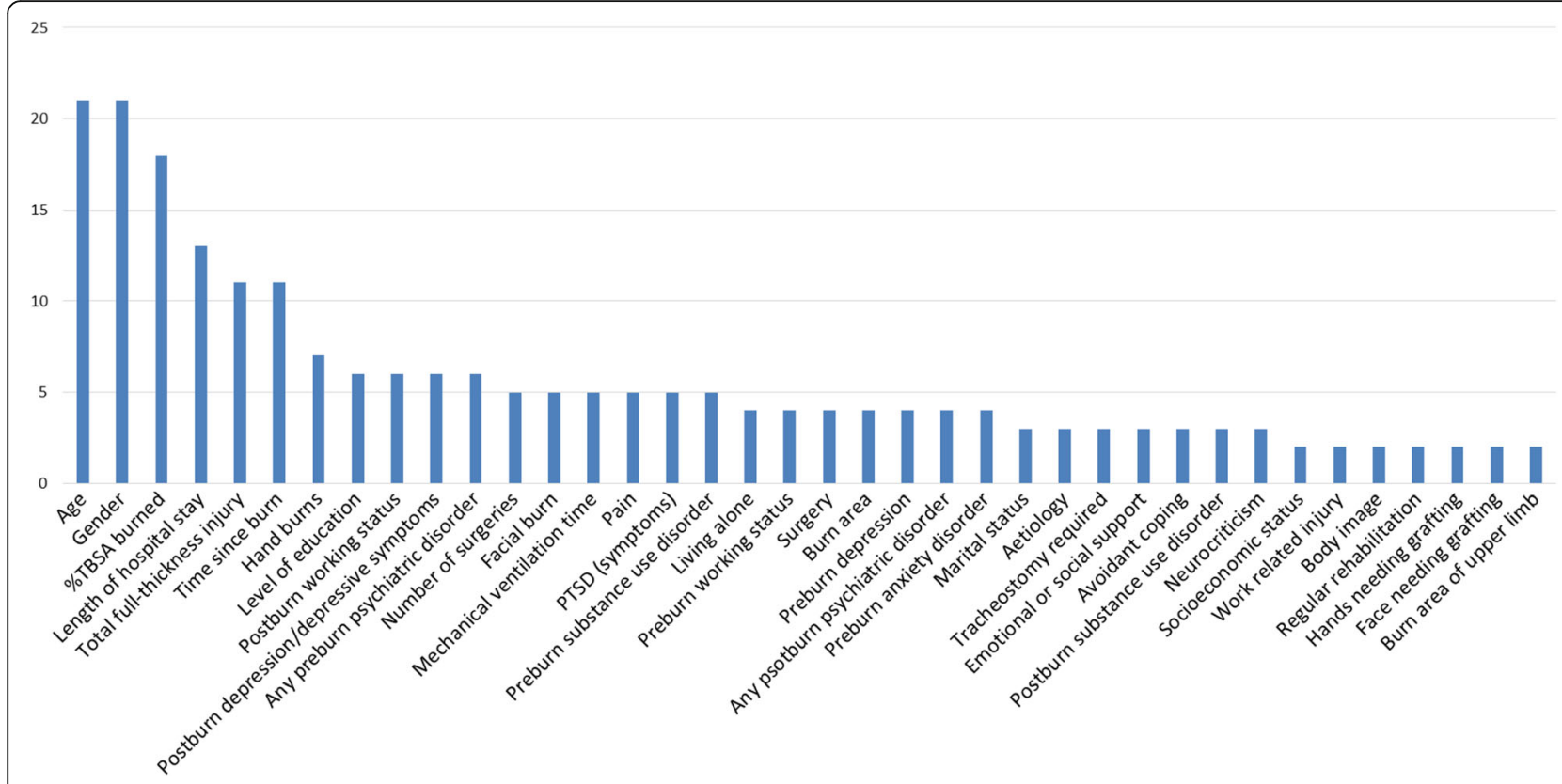

Fig. 2 Predictors investigated in more than one multivariable predictive study

included and 114 predictors were investigated in 19 studies using multivariable analysis. Among burn patients, burn severity and psychological factors and, to a lesser extent, demographic and environmental factors are related to HRQL. Severity of burns, postburn depression, posttraumatic stress symptoms, avoidance coping, less emotional or social support, higher levels of neuroticism, and unemployment postburn were found to predict poorer HRQL after burns. In addition, some weaker predictors, including female gender, pain, and a postburn substance use disorder, were identified. Other demographic and environmental factors showed in general no significant association with HRQL and the evidence was inconclusive on other burn-specific and psychological factors. The quality of these studies was in general moderate.

This review clearly indicates that the severity of burns is a strong predictor of HRQL following burns. More severe burns generally result in a poorer HRQL. It is not yet clear, however, which individual severity predictor (e.g., LOS, \%TBSA burned, number of surgeries) is best to indicate the severity of burns. By studying the multivariable results, the most optimal predictor becomes visible. The optimal predictor differed among the studies. The most consistent severity indicators for the prediction of HRQL seems to be LOS and number of surgeries. In the general trauma population, LOS is also a predictor of HRQL $[31,32]$ and there are some indications that surgical procedures predict a diminished HRQL [32]. The evidence regarding burn size was inconclusive; \%TBSA burned was found to be negatively associated with HRQL in a minority (29\%) of the studies. The other studies did not report a statistical significant association. It is remarkable that three out of the five larger studies ( $>200$ patients) reported a negative association, suggesting that \%TBSA burned is a predictor of diminished HRQL after burns. However, it is questionable whether \%TBSA burned is a good proxy for the severity of burns. It reflects the sum of the estimated percentage of full and partial thickness burns; it does not distinguish between deep and superficial wounds. Other burn-specific factors, including LOS or number of surgeries, may be better predictors [20]. Or possibly a combination of severity indicators may be the best predictor. There are also indications that having pain is a predictor for having a poorer HRQL after burns [18, 33]. It is known from other fields that patients who have severe continuing pain often also have a low HRQL [34, 35]. Other burn-specific factors, including body region burned, etiology, and longer time since burn did not generally seem to influence HRQL to a large extend.

Psychological factors are also important predictors for HRQL following burns. Five of the seven strong predictors are psychological factors, including postburn depression, posttraumatic stress symptoms, avoidance coping, less emotional or social support, and higher levels of neuroticism. These psychological factors are also predictors in other trauma populations [36-39]. Also, a postburn substance use disorder seems to be a predictor of an impaired HRQL, although evidence regarding this factor is weaker, both for burns and for trauma in general [40]. The often traumatic nature of 


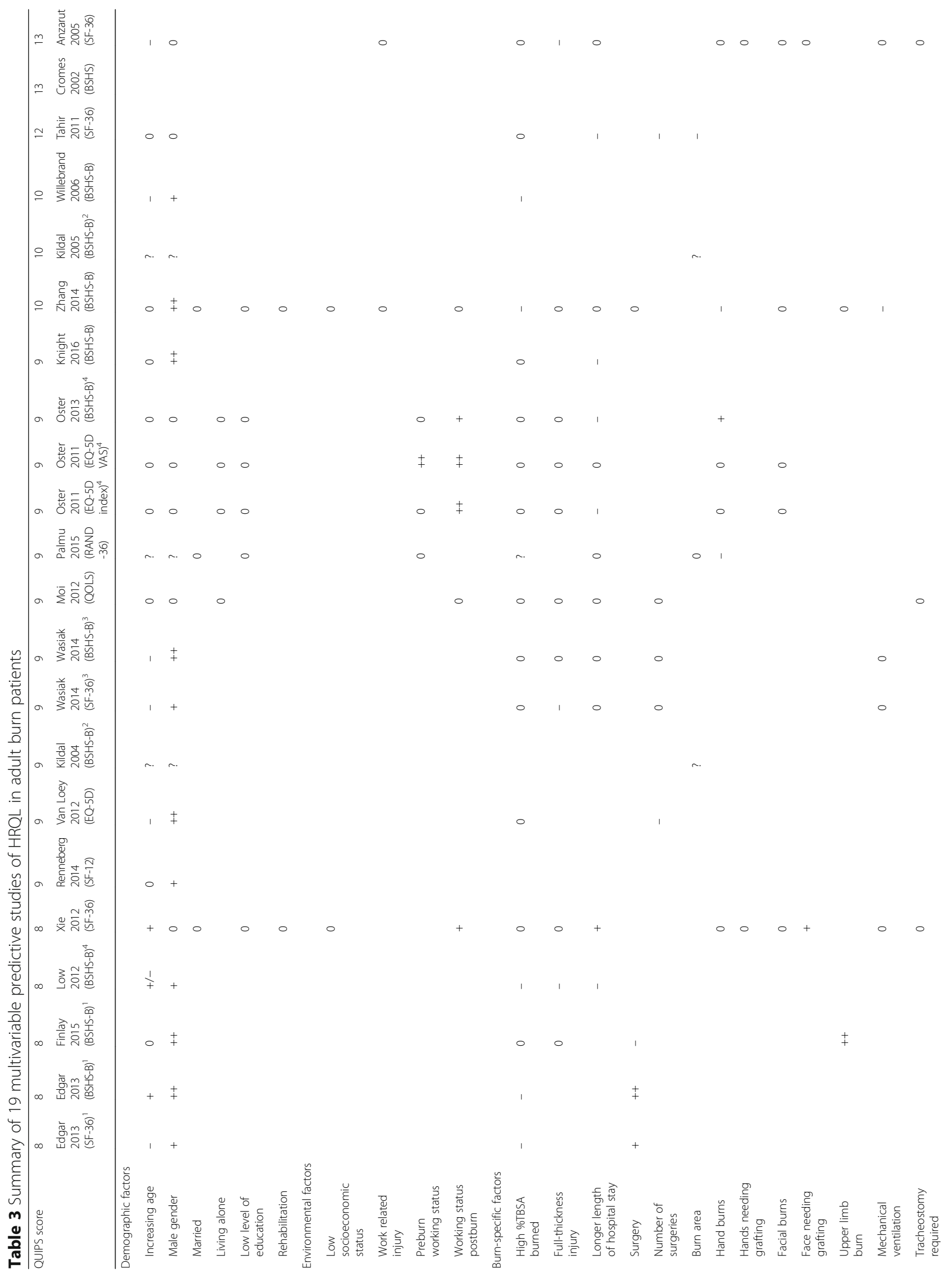




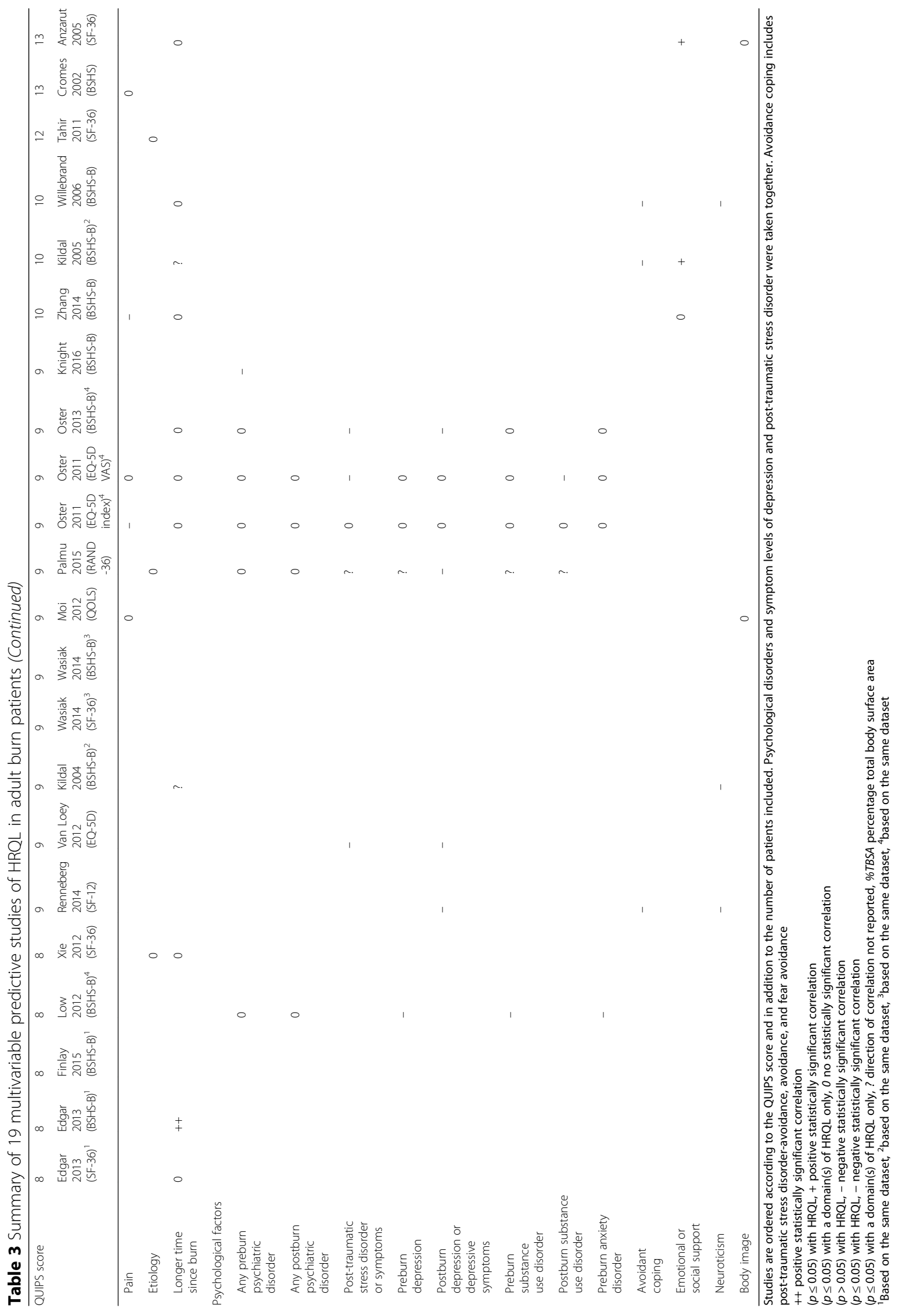


burns may result in induced psychopathological responses [41], which is related to a poorer HRQL. Psychological burden can be caused by pain, grief, change of body image, self-blame, feelings of guilt, social isolation during hospital admission, or permanent physical disabilities [41]. In addition, earlier studies showed an association between psychological and physical burden. Psychological burden was associated with delayed wound healing [42], with greater physical impairment and role disruption [43], with slower physical recovery [43], and with poorer postburn adjustment [44]. The underlying reasons for this association is not yet clear. On the one hand, psychological distress might be influenced by physical problems [45]; those who appraise their injuries as more severe might have an increased risk of psychological problems. On the other hand, individuals with psychological problems might appraise their condition as worse and their recovery as less complete, and might have a decreased intention to be involved in rehabilitation [43]. Regardless of the underlying reasons for this relationship, increased psychological burden may result in an impaired HRQL.

The only demographic predictor of HRQL after burns was gender. Females reported a poorer HRQL after burns compared to males. This finding was also found in a recent study focusing on gender differences in HRQL outcomes in burn patients [46]. Reasons for females experiencing an impaired HRQL after burns are not clear. An explanation might be that females' willingness to report problems is greater [47] or that women find it harder to live with a mutilated body. Females also reported higher levels of fatigue and higher mortality rates after burn injuries $[47,48]$. Besides, poorer outcomes in females have been shown in injury studies in general $[49,50]$. No strong conclusion could be drawn on the impact of age on HRQL after burns. Some studies reported better HRQL in younger adults, whereas others reported no or an adverse relationship. These inconsistent results are also seen in the general trauma population [31, 38, 40, 51].

Theoretically you would expect burn-specific instruments to be more sensitive to the consequences of burns. Thus, more statistically significant associations with HRQL measured by a burn-specific instrument would be expected. This was seen in the present study. Burn-specific instruments had a higher proportion of significant associations in multivariable studies. Forty-nine (47\%) significant associations out of the 104 studied associations were found when HRQL was measured with a burn-specific instrument. For generic instruments, 45 (28\%) out of the 163 studied associations were significant. The burn-specific instruments thus seem to be more sensitive compared to the generic instruments used. This finding is in line with the results of an earlier study that compared the BSHS-B against the SF-36 [52]. That study showed that SF-36 summary scores were less sensitive than the BSHS-B total score. The domain scores of the SF-36, however, were more sensitive than the domain scores of the BSHS-B [52]. Most included studies in the present review used SF-36 summary scores and BSHS-B domain scores.

The risk of bias of included studies was generally moderate. It was remarkable that none of the studies had an overall low risk of bias. In general, the risk of bias was moderate. A moderate or high risk of bias was seen particularly in the domains "study attrition" and "study confounding". Only a minority of the studies set hypotheses before testing predictors and only a few underpinned their search for predictors with the available literature. Most studies did not report how missing data were handled. Besides, confounders were often not defined, attempts to collect information on patients who dropped out were not described, and key characteristics on those lost to follow-up were not reported. Future studies should include these factors in order to decrease the risk of bias and improve the overall study quality. Another issue was the use of multivariable analysis in 20 of the 32 included studies, indicating that $38 \%$ only used univariable analysis. As HRQL is a multifactorial concept, it is likely that HRQL is influenced by several factors and therefore multivariable analysis seems indicated. Univariable analysis is not very informative due to relations among the predictors.

\section{Strengths and limitations}

A strength of this study is that it presents a comprehensive overview of predictors of a HRQL following burn injuries. Relevant literature databases were searched by an experienced librarian and quality was assessed using the widely applied QUIPS tool. A limitation is the exclusion of studies written in languages other than English, which might have resulted in missed studies published in other languages. Another limitation is the absence of a formal meta-analysis. Due to variation in instruments, time points, and data presentation in combination with the low number of studies, it was not possible to formally pool the results using meta-analysis. The examination of predictors on the basis of their direction and statistical significance that we applied does not take into account the sample size of the study nor the strength of predictors. However, we have checked that our main outcomes were not conditioned on sample size, risk of bias, or studies in the same dataset (Table 3). Due to the wide variation of assessment time points and the limited availability of short-term predictive studies, we were unable to study whether predictors differ in the short- and long-term.

\section{Conclusions}

HRQL after burn injuries is particularly affected by the severity of burns and the psychological response of an individual to the trauma. Both constructs provide unique 
information and knowledge that is necessary for optimized follow-up treatment and rehabilitation. Therefore, a comprehensive approach, including both physical and psychological care, is indicated in the aftermath of burns. Screening of patients during follow-up is valuable to identify those patients who are in need of extra rehabilitation care. Patient-oriented treatment should be given and information on HRQL should be used to enhance patient-centered decision making.

To gain further insight in individual predictors and how they are correlated with each other, future studies should be based on the best available literature or on a theoretical framework, use larger sample sizes, and ensure high methodological quality. As it is hard to collect large samples in burns, combining several existing datasets is highly recommended.

\section{Additional files}

Additional file 1: Search strategy. (DOCX $24 \mathrm{~kb}$ )

Additional file 2: Summary of 19 multivariable predictive studies of $\mathrm{HRQL}$ in adult burn patients according to time assessment points. (DOCX $43 \mathrm{~kb}$ )

\section{Abbreviations}

\%TBSA: Percentage of total body surface area; BSHS-B: Burn-specific Health Scale-Brief; HRQL: Health-related quality of life; LOS: Hospital length of stay; SF-36: Medical Outcome Study Short Form -36 items; QUIPS: Quality in Prognostic Studies

\section{Acknowledgements}

The authors gratefully acknowledge Wichor Bramer (Biomedical information specialist, Medical Library, Erasmus MC) for performing the database search.

\section{Funding}

The Dutch Burn Foundation supported in this study, grant number 15.102.

\section{Availability of data and materials}

All data analyzed during this research are included in this published article.

\section{Authors' contributions}

IS conceptualized and designed the study, collected, analyzed and interpreted the data, and drafted the manuscript. CML conceptualized and designed the study, collected, analyzed, and interpreted the data, and reviewed and revised the manuscript. JD conceptualized and designed the study and reviewed and revised the manuscript. NEL, SP, and MEB conceptualized and designed the study, analyzed and interpreted data, and reviewed and revised the manuscript. All authors read and approved the final manuscript.

\section{Competing interests}

The authors declare that they have no competing interests.

\section{Publisher's Note}

Springer Nature remains neutral with regard to jurisdictional claims in published maps and institutional affiliations.

\section{Author details}

${ }^{1}$ Association of Dutch Burn Centres, Maasstad Hospital, Maasstadweg 21, 3079 DZ Rotterdam, the Netherlands. 'Department of Public Health, Erasmus Medical Centre, 's-Gravendijkwal 230, 3015 CE Rotterdam, the Netherlands. ${ }^{3}$ Department of Plastic, Reconstructive and Hand Surgery, Amsterdam Movement Sciences, VU University Medical Centre, De Boelelaan 1117, 1081 HV Amsterdam, the Netherlands. ${ }^{4}$ Burn Centre, Maasstad Hospital, Maasstadweg 21, 3079 DZ Rotterdam, the Netherlands. ${ }^{5}$ Association of Dutch
Burn Centres, Red Cross Hospital, Vondellaan 13, 1942 LE Beverwijk, the Netherlands. 'Department of Clinical Psychology, Utrecht University, Domplein 29, 3512 JE Utrecht, the Netherlands.

Received: 22 February 2018 Accepted: 17 May 2018

Published online: 14 June 2018

\section{References}

1. Falder S, Browne A, Edgar D, Staples E, Fong J, Rea S, Wood F. Core outcomes for adult burn survivors: a clinical overview. Burns. 2009:35(5):618-41.

2. Pereira $C$, Murphy $K$, Herndon D. Outcome measures in burn care: is mortality dead? Burns. 2004;30(8):761-71.

3. Ferrans CE, Zerwic JJ, Wilbur JE, Larson JL. Conceptual model of healthrelated quality of life. J Nurs Scholarsh. 2005;37(4):336-42.

4. Guyatt $\mathrm{GH}$, Jaeschke R, Feeny DH, Patrick DL. Measurements in clinical trials: choosing the right approach. In: Spilker B, editor. Quality of life and pharmacoeconomics in clinical trials. Philadelphia: Lippincott - Raven; 1996. p. 41-8.

5. WHOQOL Group. The World Health Organization quality of life assessment (WHOQOL): position paper from the World Health Organization. Soc Sci Med. 1995;41(10):1403-9.

6. World Health Organization. International Classification of Functioning, Disability and Health: ICF: World Health Organization; 2001.

7. Wilson IB, Cleary PD. Linking clinical variables with health-related quality of life: a conceptual model of patient outcomes. JAMA. 1995;273(1):59-65.

8. Roop JC, Payne JK, Vallerand AH. Theories and conceptual models to guide quality of life research. Quality of life: from nursing and patient perspectives: theory, research, practice. Sudbury: Jones and Bartlett; 2011. p. 45-51.

9. Moi AL, Nilsen RM. Pathways leading to self-perceived general health and overall quality of life in burned adults. Burns. 2012;38(8):1157-64.

10. Van Baar M, Essink-Bot M-L, Oen I, Dokter J, Boxma H, van Beeck EF. Functional outcome after burns: a review. Burns. 2006;32(1):1-9.

11. Klinge $K$, Chamberlain DJ, Redden M, King L. Psychological adjustments made by postburn injury patients: an integrative literature review. J Adv Nurs. 2009:65(11):2274-92.

12. Jasper S, Rennekampff H-O, de Zwaan M. Psychiatric co-morbidity, body image problems and psychotherapeutic interventions for burn survivors: a review. Psychother Psychosom Med Psychol. 2013;63(11):423-8.

13. Dyster-Aas J, Kildal M, Willebrand M. Return to work and health-related quality of life after burn injury. J Rehabil Med. 2007;39(1):49-55.

14. Moi AL, Wentzel-Larsen T, Salemark L, Wahl AK, Hanestad BR. Impaired generic health status but perception of good quality of life in survivors of burn injury. J Trauma Inj Infect Crit Care. 2006;61(4):961-8.

15. Pfitzer B, Katona L, Lee SJ, O'Donnell M, Cleland H, Wasiak J, Ellen S. Three years after black Saturday: Long-term psychosocial adjustment of burns patients as a result of a major bushfire. J Burn Care Res. 2016;37(3):e244-53.

16. Sackett D, Haynes R, Guyatt G, Tugwell P. Clinical epidemiology: a basic science for clinical medicine. 2nd ed. Boston: Little, Brown \& Company; 1991.

17. Edgar DW, Homer L, Phillips M, Gurfinkel R, Rea S, Wood FM. The influence of advancing age on quality of life and rate of recovery after treatment for burn. Burns. 2013;39(6):1067-72.

18. Öster C, Willebrand M, Ekselius L. Health-related quality of life 2 years to 7 years after burn injury. J Trauma Inj Infect Crit Care. 2011;71(5):1435-41.

19. Stavrou D, Weissman O, Tessone A, Zilinsky I, Holloway S, Boyd J, Haik J. Health related quality of life in burn patients-a review of the literature. Burns. 2014:40(5):788-96.

20. Van Loey NE, van Beeck EF, Faber BW, van de Schoot R, Bremer M. Healthrelated quality of life after burns: a prospective multicenter cohort study with 18 months follow-up. J Trauma Acute Care Surg. 2012;72(2):513-20.

21. Yoder LH, Nayback AM, Gaylord K. The evolution and utility of the burn specific health scale: a systematic review. Burns. 2010;36(8):1143-56.

22. Moher D, Liberati A, Tetzlaff J, Altman DG, Prisma G. Preferred reporting items for systematic reviews and meta-analyses: the PRISMA statement. PLoS Med. 2009;6(7):e1000097.

23. Shea BJ, Reeves BC, Wells G, Thuku M, Hamel C, Moran J, Moher D, Tugwell $P$, Welch V, Kristjansson E. AMSTAR 2: a critical appraisal tool for systematic reviews that include randomised or non-randomised studies of healthcare interventions, or both. BMJ. 2017;358:j4008.

24. Hayden JA, van der Windt DA, Cartwright $J$, Côté $P$, Bombardier C. Assessing bias in studies of prognostic factors. Ann Intern Med. 2013;158(4):280-6. 
25. Hedges L, Olkin I. Meta analysis: a review and a new view. Educ Researcher. 1986;15(8):14-6.

26. Taylor RS, Sander JW, Taylor RJ, Baker GA. Predictors of health-related quality of life and costs in adults with epilepsy: A systematic review. Epilepsia. 2011; 52(12):2168-80.

27. Ahuja RB, Mulay AM, Ahuja A. Assessment of quality of life (QoL) of burn patients in India using BSHS-RBA scale. Burns. 2016;42(3):639-47.

28. Orwelius L, Willebrand M, Gerdin B, Ekselius L, Fredrikson M, Sjöberg F. Long term health-related quality of life after burns is strongly dependent on preexisting disease and psychosocial issues and less due to the burn itself. Burns. 2013;39(2):229-35.

29. Ekeblad F, Gerdin B, Öster C. Impact of personality disorders on health-related quality of life one year after burn injury. Disabil Rehabil. 2015;37(6):534-40.

30. Öster C, Willebrand M, Ekselius L. Burn-specific health 2 years to 7 years after burn injury. J Trauma Acute Care Surg. 2013;74(4):1119-24.

31. Gunning A, van Heijl M, van Wessem K, Leenen L. The association of patient and trauma characteristics with the health-related quality of life in a Dutch trauma population. Scand J Trauma Resusc Emerg Med. 2017; 25(1):41.

32. Sluys K, Häggmark T, Iselius L. Outcome and quality of life 5 years after major trauma. J Trauma Acute Care Surg. 2005;59(1):223-32.

33. Zhang LJ, Cao J, Feng P, Huang J, Lu J, Lu XY, Xia ZF. Influencing factors of the quality of life in Chinese burn patients: Investigation with adapted Chinese version of the BSHS-B. Burns. 2014;40(4):731-6.

34. Becker N, Thomsen AB, Olsen AK, Sjøgren P, Bech P, Eriksen J. Pain epidemiology and health related quality of life in chronic non-malignant pain patients referred to a Danish multidisciplinary pain center. Pain. 1997; 73(3):393-400

35. Erosa NA, Berry JW, Elliott TR, Underhill AT, Fine PR. Predicting quality of life 5 years after medical discharge for traumatic spinal cord injury. $\mathrm{Br} J$ Health Psychol. 2014;19(4):688-700.

36. Kenardy J, Heron-Delaney M, Hendrikz J, Warren J, Edmed SL, Brown E. Recovery trajectories for long-term health-related quality of life following a road traffic crash injury: Results from the UQ SuPPORT study. J Affect Disord. 2017;214:8-14

37. Kiely JM, Brasel KJ, Weidner KL, Guse CE, Weigelt JA. Predicting quality of life six months after traumatic injury. J Trauma Acute Care Surg. 2006;61(4):791-8.

38. Tøien K, Bredal IS, Skogstad L, Myhren H, Ekeberg $\varnothing$. Health related quality of life in trauma patients. Data from a one-year follow up study compared with the general population. Scand J Trauma Resusc Emerg Med. 2011; 19(1):22.

39. Neria Y, Nandi A, Galea S. Post-traumatic stress disorder following disasters: a systematic review. Psychol Med. 2008;38(4):467-80.

40. Willemse-van Son AHP, Ribbers GM, Verhagen AP, Stam HJ. Prognostic factors of long-term functioning and productivity after traumatic brain injury: a systematic review of prospective cohort studies. Clin Rehabil. 2007; 21(11):1024-37.

41. Van Loey NEE, Van Son MJM. Psychopathology and psychological problems in patients with burn scars. Am J Clin Dermatol. 2003;4(4):245-72.

42. Walburn J, Vedhara K, Hankins M, Rixon L, Weinman J. Psychological stress and wound healing in humans: a systematic review and meta-analysis. J Psychosom Res. 2009;67(3):253-71.

43. Fauerbach JA, Lezotte D, Hills RA, Cromes GF, Kowalske K, De Lateur BJ, Goodwin CW, Blakeney P, Herndon DN, Wiechman SA. Burden of burn: a norm-based inquiry into the influence of burn size and distress on recovery of physical and psychosocial function. J Burn Care Res. 2005; 26(1):21-32.

44. Fauerbach JA, Lawrence J, Haythornthwaite J, McGuire M, Munster A. Preinjury psychiatric illness and postinjury adjustment in adult burn survivors. Psychosomatics. 1996:37(6):547-55.

45. Cohen S, Rodriguez MS. Pathways linking affective disturbances and physical disorders. Health Psychol. 1995;14(5):374.

46. Wasiak J, Lee SJ, Paul E, Shen A, Tan H, Cleland H, Gabbe B. Female patients display poorer burn-specific quality of life 12 months after a burn injury. Injury. 2017;48(1):87-93.

47. Gabbe BJ, Cleland H, Watterson D, Schrale R, McRae S, Taggart S, Darton A, Wood F, Edgar DW. Predictors of moderate to severe fatigue 12 months following admission to hospital for burn: results from the Burns Registry of Australia and New Zealand (BRANZ) Long Term Outcomes project. Burns. 2016;42(8):1652-61.
48. Moore EC, Pilcher DV, Bailey MJ, Stephens H, Cleland H. The Burns Evaluation and Mortality Study (BEAMS): predicting deaths in Australian and New Zealand burn patients admitted to intensive care with burns. J Trauma Acute Care Surg. 2013;75(2):298-303.

49. Polinder S, van Beeck EF, Essink-Bot ML, Toet H, Looman CW, Mulder S, Meerding WJ. Functional outcome at 2.5, 5, 9, and 24 months after injury in the Netherlands. J Trauma Acute Care Surg. 2007;62(1):133-41.

50. Holbrook TL, Hoyt DB, Anderson JP. The importance of gender on outcome after major trauma: functional and psychologic outcomes in women versus men. J Trauma Acute Care Surg. 2001;50(2):270-3.

51. Polinder $\mathrm{S}$, van Beeck EF, Essink-Bot ML, Toet H, Looman CWN, Mulder S, Meerding WJ. Functional outcome at 2.5, 5, 9, and 24 months after injury in the Netherlands. J Trauma Acute Care Surg. 2007;62(1):133-41.

52. Edgar D, Dawson A, Hankey G, Phillips M, Wood F. Demonstration of the validity of the SF-36 for measurement of the temporal recovery of quality of life outcomes in burns survivors. Burns. 2010;36(7):1013-20.

53. Anzarut A, Chen M, Shankowsky H, Tredget EE. Quality-of-life and outcome predictors following massive burn injury. Plast Reconstr Surg. 2005;116(3):791-7.

54. Blalock SJ, Bunker BJ, DeVellis RF. Measuring health status among survivors of burn injury: revisions of the Burn Specific Health Scale. J Trauma Acute Care Surg. 1994;36(4):508-15.

55. Corry NH, Klick B, Fauerbach JA. Posttraumatic stress disorder and pain impact functioning and disability after major burn injury. J Burn Care Res. 2010;31(1):13-25.

56. Cromes GF, Holavanahalli R, Kowalske K, Helm P, Doctor M, Lawrence JW, Fauerbach JA. Predictors of quality of life as measured by the burn specific health scale in persons with major burn injury. J Burn Care Rehabil. 2002; 23(3):229-34.

57. Finlay V, Phillips M, Wood F, Hendrie D, Allison G, Edgar D. Enhancing the clinical utility of the Burn Specific Health Scale-Brief: not just for major burns. Burns. 2014;40(2):328-36.

58. Finlay V, Phillips M, Allison G, Wood F, Ching D, Wicaksono D, Plowman S, Hendrie D, Edgar D. Towards more efficient burn care: identifying factors associated with good quality of life post-burn. Burns. 2015;41(7): 1397-404.

59. Kildal M, Andersson G, Fugl-Meyer AR, Lannerstam K, Gerdin B. Development of a brief version of the Burn Specific Health Scale (BSHS-B). J Trauma Acute Care Surg. 2001;51(4):740-6.

60. Kildal M, Willebrand M, Andersson G, Gerdin B, Ekselius L. Personality characteristics and perceived health problems after burn injury. J Burn Care Rehabil. 2004;25(3):228-35.

61. Kildal M, Willebrand M, Andersson G, Gerdin B, Ekselius L. Coping strategies, injury characteristics and long-term outcome after burn injury. Injury. 2005; 36(4):511-8.

62. Knight A, Wasiak J, Salway J, O'Brien L. Factors predicting health status and recovery of hand function after hand burns in the second year after hospital discharge. Burns. 2017:43(1):100-6.

63. Leblebici B, Adam M, Baǧiş S, Tarim AM, Noyan T, Akman MN, Haberal MA Quality of life after burn injury: the impact of joint contracture. J Burn Care Res. 2006;27(6):864-8.

64. Low AJF, Dyster-Aas J, Willebrand M, Ekselius L, Gerdin B. Psychiatric morbidity predicts perceived burn-specific health 1 year after a burn. Gen Hosp Psychiatry. 2012;34(2):146-52.

65. Moi AL, Wentzel-Larsen T, Salemark L, Hanestad BR. Long-term risk factors for impaired burn-specific health and unemployment in patients with thermal injury. Burns. 2007;33(1):37-45.

66. Novelli B, Melandri D, Bertolotti G, Vidotto G. Quality of life impact as outcome in burns patients. G Ital Med Lav Ergon. 2009;31(1 SUPPL. A):A58-63.

67. Palmu R, Partonen T, Suominen K, Saarni SI, Vuola J, Isometsä E. Healthrelated quality of life 6 months after burns among hospitalized patients: Predictive importance of mental disorders and burn severity. Burns. 2015; 41(4):742-8.

68. Renneberg B, Ripper S, Schulze J, Seehausen A, Weiler M, Wind G, Hartmann B, Germann G, Liedl A. Quality of life and predictors of long-term outcome after severe burn injury. J Behav Med. 2014;37(5):967-76.

69. Ricci H, Gonçalves N, Gallani MC, Ciol MA, Dantas RAS, Rossi LA. Assessment of the health status in Brazilian burn victims five to seven months after hospital discharge. Burns. 2014:40(4):616-23.

70. Roh YS, Chung HS, Kwon B, Kim G. Association between depression, patient scar assessment and burn-specific health in hospitalized burn patients. Burns. 2012;38(4):506-12. 
71. Tahir SM, Memon MM, Ali SA, Rasheeed S. Health related quality of life after burns: are we really treating burns? J Ayub Med Coll Abbottabad. 2011; 23(2):152-6.

72. Wasiak J, Lee SJ, Paul E, Mahar P, Pfitzer B, Spinks A, Cleland H, Gabbe B. Predictors of health status and health-related quality of life 12 months after severe burn. Burns. 2014;40(4):568-74.

73. Willebrand M, Andersson G, Kildal M, Gerdin B, Ekselius L. Injury-related fearavoidance, neuroticism and burn-specific health. Burns. 2006;32(4):408-15.

74. Willebrand $M$, Ekselius $L$. Health-related quality of life 2 years to 7 years after burn injury. J Trauma Acute Care Surg. 2011;71(5):1435-41.

75. Xie B, Xiao SC, Zhu SH, Xia ZF. Evaluation of long term health-related quality of life in extensive burns: A 12-year experience in a burn center. Burns. 2012;38(3):348-55. 